\title{
UPAYA PERBAIKAN DALAM MENENTUKAN AKAR MASALAH PADA GURU DENGAN MENGUNAKAN TOOLS DALAM MANAJEMEN MUTU TERPADU \\ DI SMK ABC KOTA $X$
}

\author{
Bahrul Ulum Falahul Putra \\ Ahmad Supriyanto \\ Agus Timan \\ Email: bahrululumfalahulputra@gmail.com \\ Universitas Negeri Malang, Jl. Semarang No. 5 Malang 65I45
}

\begin{abstract}
In improving the integrated quality management closely related to human resource problems that occur in SMK ABC Kota $X$. This analysis is intended to solve the problem in schools to improve the quality of education. The procedure of this study used interviews and analysis using tree diagrams and 5 why's. The results of this study are based on the findings of problems in schools regarding teacher motivation that are still low. Based on these findings the school is expected to be able to address the problem with the right solution.
\end{abstract}

Keywords: Management, Quality, Education.

Abstrak: Dalam meningkatkan manajemen mutu terpadu erat kaitannya dengan problematika sumber daya manusia yang terjadi di SMK ABC Kota $X$. Analisis ini bertujuan untuk menyelesaikan masalah yang terdapat di sekolah untuk meningkatkan mutu pendidikan. Prosedur penelitian ini menggunakan wawancara dan analisis menggunakan diagram pohon dan analisis 5 mengapa. Hasil dari penelitian ini dihasilkan berdasarkan temuan masalah di sekolah mengenai motivasi kerja guru yang masih rendah. Berdasarkan temuan tersebut sekolah diharapkan dapat menyikapi permasalahan dengan penyelesaian yang tepat.

Kata kunci: Manajemen, Mutu, Pendidikan.

\section{PENDAHULUAN}

Pendidikan adalah proses memunculkan dan mengembangkan potensi peserta didik yang diperlukannya untuk menjalani kehidupan yang bermartabat (Satori, 2016:134). Pendidikan adalah salah satu pokok dasar kebutuhan bagi seluruh warga negara, oleh karena itu penyelengaraan pendidikan merupakan kepentingan nasional sehingga, setiap insan yang lahir di bumi pertiwi ini berhak mendapatkan pendidikan tanpa membeda-bedakan siapapun mereka dan dijamin oleh negara berdasarkan UUD 1945 pasal 31. Hal ini merupakan tanggung-jawab penuh lembaga pendidikan untuk memberikan pelayanan pendidikan yang bermutu/berkualitas kepada peserta didik.

Menurut Satori (2016:135) dalam perspektif mikro, mutu pendidikan berkaitan dengan mutu layanan pembelajaran. Jadi, perhatian penuh diberikan kepada peserta didik, dan ada jaminannya bahwa peserta didik memang benar-benar mengalami proses belajar yang bermutu. Dalam Permendikbud nomor 28 tahun 2016 pasal I ayat I menyebutkan bahwa Mutu Pendidikan Dasar dan Menengah adalah tingkat kesesuaian, antara penyelenggaraan pendidikan dasar dan pendidikan menengah dengan Standar Nasional Pendidikan pada pendidikan dasar dan pendidikan menengah. Agar terwujudnya harapan tentang mutu terhadap pendidikan ini, pemerintah telah menetapkan sebuah Standar Nasional Pendidikan (SNP) di Indonesia yang dimuat dalam Peraturan Pemerintah Republik Indonesia No. 13 tahun 2015, yang terdiri atas 8 standar yaitu: I. Standar Kompetensi Lulusan; 2. Standar Isi; 3. Standar Proses; 4. Standar Pendidik dan Tenaga Kependidikan; 5. Standar Sarana dan Prasarana; 6. Standar Pengelolaan; 7. Standar pembiayaan; dan 8. Standar Penilaian. Mutu 
pendidikan sesungguhnya ditentukan oleh mutu belajar peserta didik/ siswa dalam belajar. Oleh karena itu, semua standar tersebut diatas akan menentukan peserta didik yang bermutu/berkualitas.

Dalam memenuhi mutu pendidikan tersebut di atas, proses pelaksanaan pendidikan sangat penting peran guru yang profesional. Berdasarkan UU No. 14 tahun 2005 tentang Guru dan Dosen dijelaskan bahwa guru merupakan pendidik profesional dengan tugas utamanya mendidik, mengajar, membimbing, mengarahkan, melatih, serta menilai, dan mengevaluasi anak didiknya. Kata "professional" menurut KBBI adalah memerlukan kepandaian secara khusus untuk menjalankannya. Profesional adalah pekerjaan (kegiatan) yang dilakukan oleh orang yang membutuhkankan keahlian, kemahiran (kecakapan) yang memenuhi standar mutu (Husien, 2017:14). Jadi, guru yang profesional adalah seorang guru yang mempunyai kepandaian khusus, ahli, mahir atau cakap dalam mengajar.

\section{Mengidentifikasi masalah yang terjadi di SMK ABC Kota $X$}

SMK ABC Kota $X$ merupakan sekolah yang berlokasi di jl. SLG no. 45 Kota $X$. Setelah melakukan observasi dan wawancara, peneliti mendaftar sejumlah permasalah ditulis pada kertas periksa (check sheet). Kertas periksa yaitu sebuah alat yang paling mudah dalam menghitung seberapa seringkah sesuatu/ masalah tersebut terjadi. Dengan demikian kertas periksa adalah alat yang paling sederhana, tetapi teratur untuk mengumpulkan dan mencatat data untuk mengetahui masalah utama (Hunt, dalam Nasution 20 I5: I33).

Tabel I. Identifikasi masalah menggunakan kertas periksa (check sheet)

\begin{tabular}{|l|l|l|l|}
\hline No. & Type of Deffect & Count & Score \\
\hline I. & Banyak guru resign & IIIII IIIII III & I3 \\
\hline 2. & Banyak jam kosong & IIIII IIIII II & I2 \\
\hline 3. & Guru tidak membuat perangkat pembelajaran & IIIII IIIII I & II \\
\hline 4. & Belum tersedianya perpustakaan & IIIII II & 7 \\
\hline 5. & Guru datang terlambat pada saat mengajar & IIIII IIIII II & I2 \\
\hline
\end{tabular}

Dari hasil tabel diatas diketahui bahwa banyak guru resign sering terjadi dan menjadi masalah yang selalu dihadapi secara berkelanjutan oleh sekolah tersebut dan masalah yang kedua adalah banyaknya jam kosong dan guru sering datang terlambat pada saat mengajar. Masalah ketiga guru tidak membuat perangkat pembelajaran dan terakhir belum tersedianya perpustakaan. Secara keseluruhan beberapa pokok permasalah-permasalah yang ditemukan oleh peneliti di lapangan bukanlah sumber masalah, akan tetapi dampak yang dihasikan dari sebuah masalah yang belum teratasi/terselesaikan. Maka dapat di tarik kesimpulan kurangnya ketersediaan guru memicu dampak yang terjadi pada masalah-masalah yang ada pada kertas periksa (check sheet). Sehingga kurangnya ketersediaan guru akan berdampak pada rendahnya mutu pendidikan sekolah tersebut

\section{METODE}

Menurut Nasution (2015: 133) alat perbaikan kualitas pendidikan dibedakan berdasarkan alat yang menggunakan data numerik dan alat yang menggunakan data verbal. Ada lima alat yang digunakan untuk mengolah data numerik / data kuantitatif yaitu menggunakan kertas periksa, diagram perjalanan (run chart), histogram, diagram pencar dan pareto chart. Sedangkan alat dalam menggunakan serta mengelola data verbal adalah diagram 
pohon (tree diagrams), brainstorming, diagram tulang ikan (fishbone diagrams), bagan alur, dan diagram gabungan. Dari alat perbaikan kualitas pendidikan ini, maka teknik dan alat perbaikan kualitas pada lembaga sekolah tersebut, yang digunakan untuk menentukan pokok dan akar dari sebuah masalah adalah diagram pohon. Menurut Nasution (2015: 146) diagram pohon (tree diagrams) berfungsi untuk mengkaitkan antara tujuan dengan tugas yang harus dilaksanakan dalam mencapai tujuan tersebut. Menurut Kho (2016) salah satu kegunaan diagram pohon adalah membantu untuk menemukan akar permasalahan serta menjabarkan langkah yang harus dilakukan/ diperlukan dalam menyelesaikan sebuah permasalahan yang terjadi. Pada saat peneliti mendalami mini riset dari sumber masalah yaitu kurangnya jumlah ketersediaan guru pada SMK ABC Kota $X$, peneliti menemukan 2 akar dari masalah yang terjadi di sekolah tersebut. Akar masalah yang pertama adalah banyak guru resign dan akar

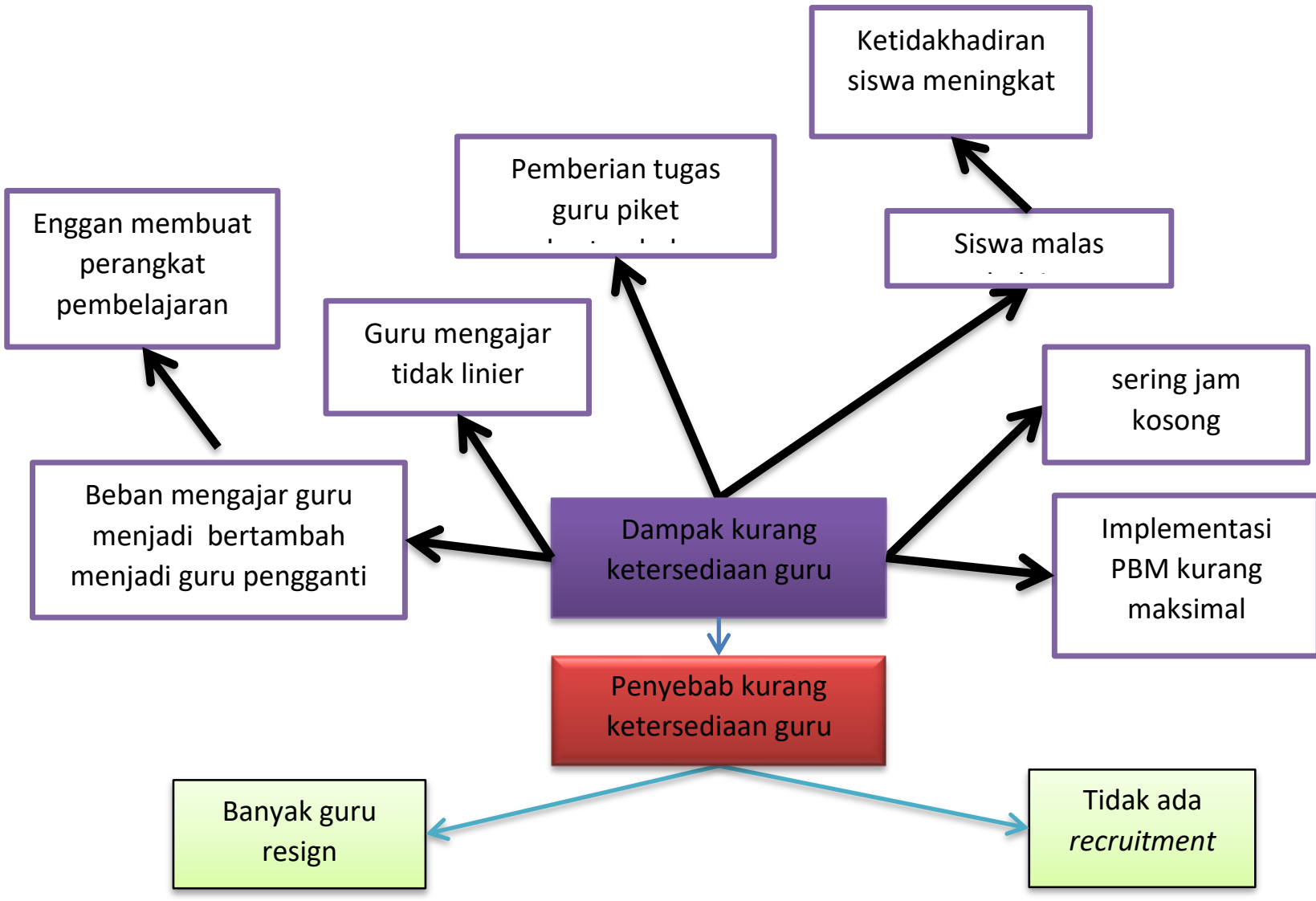

masalah kedua yaitu tidak ada recruitment. Untuk memudahkan pembaca dalam memahami maka peneliti menyajikan dalam sebuah gambar diagram pohon yang terlihat seperti pada gambar dibawah ini.

Gambar I. Hubungan sebab akibat menggunakan diagram pohon

\section{HASIL DAN PEMBAHASAN}

Berdasarkan analisis permasalahan menggunakan diagram pohon di atas masalah utama yaitu kurangnya ketersediaan guru. Permasalahan ini dihadapi oleh hampir seluruh guru di dalam SMK ABC Kota $X$ bahkan bisa jadi di sekolah swasta yang lain juga sama. Untuk memaksimalkan hasil data yang sudah ada, maka peneliti menggali akar masalah sampai dengan menemukan solusinya. Maka dari itu dipilihlah teknik analisis 5 mengapa (5 why's analysis) untuk mendukung dalam menelusuri serta menghubungkan sebab-akibat yang menjadi akar dari sebuah permasalahan tersebut dengan teknik bertanya dan menjawab secara sederhana. Teknik yang digunakan ini merupakan praktik bertanya mengapa sampai dengan lima kali secara terus menerus, mengapa sebuah masalah baik teknis maupun non- 
teknis terjadi dalam upaya penentuan akar dari penyebab suatu kerusakan / masalah. Teknik yang dikembangkan oleh Sakichi Toyoda yang kemudian digunakan di dalam perusahaan Toyota Motor Corporation serta strategi ini dipopulerkan oleh Sistem Produksi Toyota pada tahun 1970-an. Dan metode ini, sekarang digunakan sebagai salah satu metode dalam Six Sigma strategy.

Berikut hasil analisis pemecahan masalah dengan menggunakan teknik analisis 5 mengapa (5 why's analysis) yaitu:

Analisis penyebab pertama adalah :

Mengapa kurangnya jumlah ketersediaan guru?

I. Karena banyak guru yang resign

Mengapa banyak guru yang resign?

2. Karena suasana sekolah yang kurang nyaman untuk bekerja

Mengapa suasana sekolah yang kurang nyaman?

3. Warga sekolah mulai membentuk kelompok-kelompok tertentu

Mengapa warga sekolah mulai membentuk kelompok-kelompok tertentu?

4. Cara dan keterampilan berkomunikasi kurang baik pada individu ke individu maupun individu ke kelompok

Mengapa cara dan keterampilan berkomunikasi kurang baik?

5. Karena kurang berinteraksi dan datang ke sekolah hanya mengajar saja

Analisis penyebab kedua adalah :

Mengapa kurangnya jumlah ketersediaan guru?

I. Karena tidak ada recruitment

Mengapa tidak ada recruitment?

2. Karena programnya masih belum berjalan

Mengapa programnya belum jalan?

3. Karena tidak ada pelaksananya

Mengapa tidak ada pelaksana?

4. Karena ada anggapan perlu orang khusus

Mengapa ada anggapan perlu orang khusus?

5. Karena kurang sosialisasi dan belum adanya petunjuk teknisnya

Pada penyebab pertama ada kemungkinan munculnya kelompok-kelompok dalam guru ataupun pada seluruh warga sekolah. Agar dinamika dalam suatu kelompok menjadi efektif dengan perilaku anggotanya yang kondusif untuk mencapai sebuah tujuan dari organisasi, maka diperlukan semangat, rasa kebersamaan dan komitmen untuk berkerja keras. Pada penyebab kedua, selain karena kurang sosialisasi dan belum adanya petunjuk teknisnya, maka memerlukan adanya sebuah kejelasan dalam pekerjaan/ tugas dari masing-masing individu maupun kelompok, sehingga dapat lebih mudah ketercapaian tujuan dari suatu organisasi bisa dikoordinasikan dengan baik.

Oleh sebab itu, peran kepemimpinan yang kurang merupakan masalah strategis dalam menggerakkan dinamika kelompok. Seorang pemimpin sangat berperan posisinya dalam mempengaruhi serta menggerakkan individu-individu, termasuk mempengaruhi perilaku kelompok dalam suatu organisasi. Perilaku kelompok harus dikelola dengan baik, meskipun nantinya akan muncul perbedaan pada pandangan maupun sikap beserta perilaku antar kelompok di dalam organisasi. Pemimpin organisasi memegang posisi sentral dalam tugas organisasi, karena dia merupakan orang yang memiliki tanggung jawab mempengaruhi orang lain/ kelompok dalam mencapai tujuan organisasi tersebut.

Peran kepala sekolah yang menjadi seorang pimpinan/ manager pada suatu sekolah harusnya berupaya menanggulangi masalah tersebut agar tidak dampak ke pihak lain. Upaya perbaikan/ solusi yang diambil yaitu pada guru resign salah satunya adalah dengan membuat sebuah kegiatan bersama-sama yang diikuti seluruh warga sekolah. Melalui kegiatan non- 
formal itulah seluruh guru bisa berkomunikasi dan sosialisasi kepada sesama guru maupun tanpa adanya batasan dengan pimpinan agar seluruh warga sekolah dapat menciptakan suasana kekeluargaan yang nyaman. Sehingga guru menjadi betah dan enggan untuk pindah pekerjaan serta meningkatkan motivasi dan keprofesionalan sebagai guru di sekolah. Dan untuk akar masalah kedua yaitu tidak ada recruitment, solusi yang ditawarkan adalah melalui Kepala Sekolah membuat dan menyiapkan perangkat penilaian calon guru baru/ guru penganti untuk direkrut apabila sumber daya yang ada di sekolah tidak dapat meng-cover guru yang keluar/ resign. Sehingga program yang belum berjalan ini dapat dilaksanakan tanpa harus menunggu pergantian semester/ mendekati tahun ajaran baru untuk melaksanakan program open recruitment. Dan Kepala Sekolah memberikan perangkat tadi agar asumsi anggapan orang khusus tidak muncul pada pikiran para wakilnya karena sudah menunjuk salah satu wakilnya untuk menjalankan tugas tersebut dapat berjalan ketika keadaan mendesak (urgent).

Apabila ditarik benang merahnya maka hasil dari pendalaman menentukan penyebab / mengapa masalah itu muncul sampai dengan solusi yang ditawarkan, akan terlihat pada gambar di bawah ini 


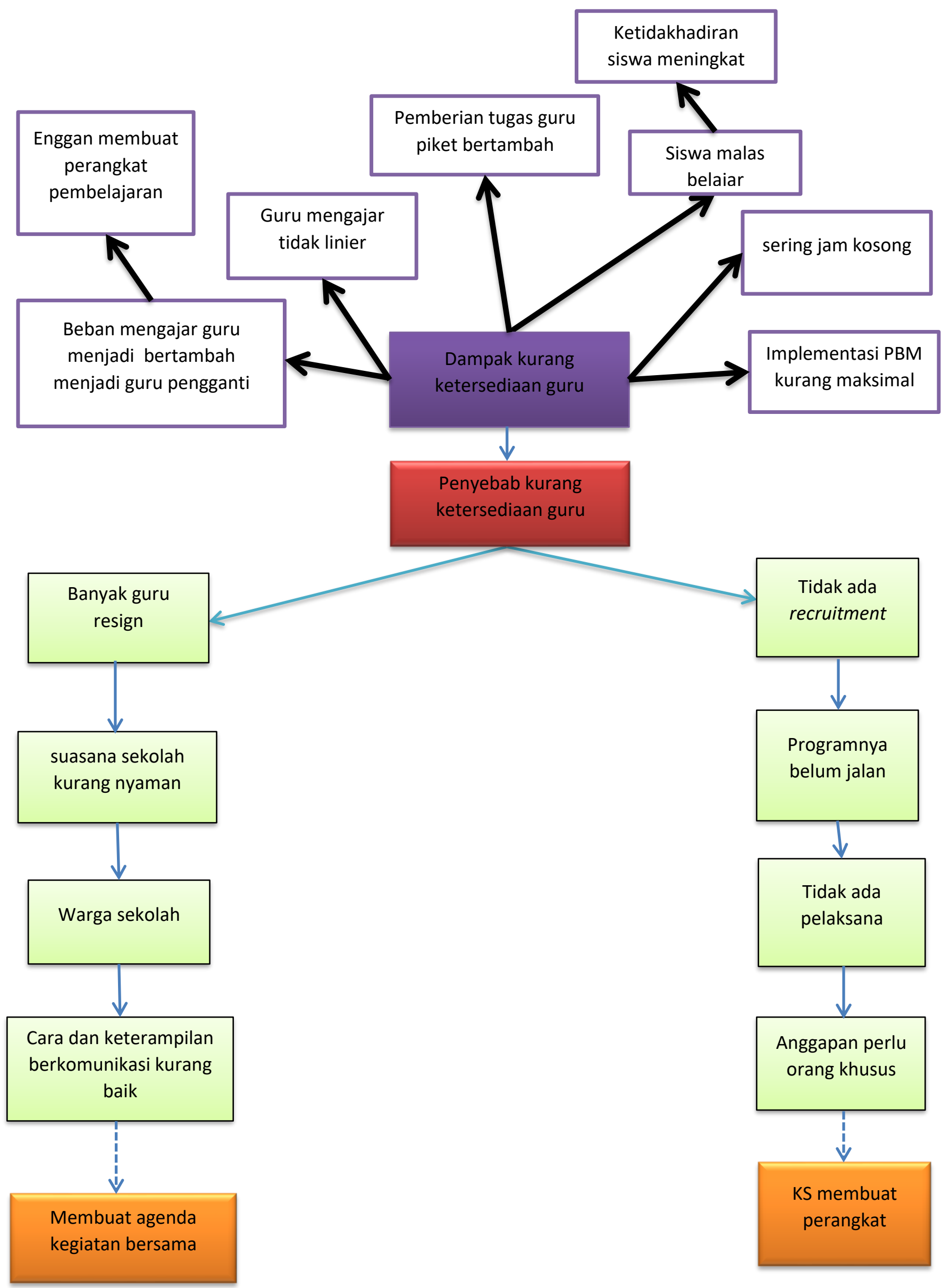

Gambar 2. Hasil penyebab, dampak, akar masalah, dan cara penyelesaian 


\section{KESIMPULAN}

Permasalahan SDM merupakan masalah sering terjadi dalam suatu pengelolaan organisasi atau instansi. Hal ini juga terjadi di SMK ABC Kota $X$. Dalam berbagai bidang pekerjaan dengan kata lain profesionalisme merupakan suatu keahlian khusus sesuai bidang tugas atau pekerjaannya. Sedangkan tugas utama guru ialah mengajar, mendidik, dan membimbing mulai dari hal akademik hingga non akademik, sehingga keprofesionalan guru benar-benar harus dioptimalkan. Melalui hasil pengamatan, bahwa masih ada guru yang lalai akan tanggung jawabnya. Mengajar tidak sesuai dengan tupoksi, tidak sesuai dengan rencana pembelajaran. Untuk Menindaklanjuti temuan ini, peneliti mengadakan analisis menggunakan diagram Diagram Pohon dan 5 why's analysis. Kemudian observer menemukan solusi pemecahan masalah untuk meningkatkan mutu di SMK ABC Kota $X$. Dalam analisis menggunakan diagram diatas, permasalahan yang ditemukan ada 2 sub penyebab masalah utama adalah individu guru dan peran kepala sekolah dengan solusi, (I) membuat agenda kegiatan bersama-sama (2) kepala sekolah membuat perangkat kualifikasi dan penilaian pada penerimaan guru baru.

\section{DAFTAR RUJUKAN}

Kho, B. 2016. Pengertian Diagram Pohon (Tree Diagram) dan Cara Membuatnya. (Online). (https://ilmumanajemenindustri.com/pengertian-diagram-pohon-tree-diagram-caramembuat-diagram-pohon/). Diakses 4 Maret 2019

Liker, Jeffrey K. (2006). The Toyota Way: 4 Management Principles from the World's Greatest Manufacturer. Penerbit Erlangga. hlm. 306.

Mintorogo, A. Kepemimpinan dalam Organisasi. Jakarta: STIA LAN Press.

Nasution, N. M. 2015. Manajemen Mutu Terpadu (Total Quality Management). Bogor: Ghalia Indonesia

Rivai, V. 2004. Kepemimpinan dan Perilaku Organisasi Jakarta: RT. Raja Grafindo Persada

Robbins, S. 1996. Perilaku Organisasi: Konsep, Kontroversi, Aplikasi, terjemahan Hadyana

Pudjaatmika. Jakarta: Bumi Aksara.

Serrat, Olivier (2009). "The Five Whys Technique" (PDF). Asian Development Bank. Diakses tanggal 2013-09-04.

Undang Undang No. 14 tahun 2005 tentang Guru dan Dosen 